\title{
Coulisses
}

Revue de théâtre

7| Printemps 1993

Varia

\section{De Buffo à Buten}

Espace Planoise Besançon 19-20-21 novembre 1992

\section{Anne-Marie Tournier}

\section{CpenEdition}

\section{Journals}

Édition électronique

URL : http://journals.openedition.org/coulisses/2182

DOI : $10.4000 /$ coulisses. 2182

ISSN : 2546-9460

Éditeur

Presses universitaires de Franche-Comté

\section{Édition imprimée}

Date de publication : 1 avril 1993

Pagination : 12-13

ISSN : 1150-594X

Référence électronique

Anne-Marie Tournier, « De Buffo à Buten », Coulisses [En ligne], 7 | Printemps 1993, mis en ligne le 15 mars 2019, consulté le 27 octobre 2019. URL : http://journals.openedition.org/coulisses/2182 ; DOI : $10.4000 /$ coulisses. 2182

Ce document a été généré automatiquement le 27 octobre 2019

Coulisses 


\section{De Buffo à Buten}

Espace Planoise Besançon 19-20-21 novembre 1992

\section{Anne-Marie Tournier}

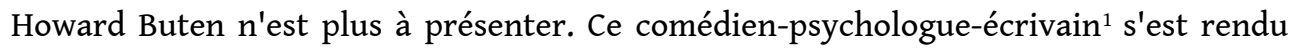
célèbre dans ces trois domaines. Mais mon propos se bornera à parler du comédien, car c'est lui que l'Espace Besançon Planoise accueillait.

\section{Buffo - Le clown}

1 Howard Buten, donc est clown depuis plus de vingt ans. Mais il estime qu'il n'est un «vrai clown» que depuis sept ou huit ans. C'est à dire que Buffo «existe» à part entière, aux yeux des spectateurs. Le comédien n'apparaît plus du tout derrière le personnage et celui-ci «fonctionne », il est crédible, il a acquis son indépendance en quelque sorte! Parce que le spectacle de Buten n'est pas fondé sur une histoire qu'il raconterait mais sur un personnage. Et celui-ci évolue, vit sous nos yeux. Il progresse de gags en gags. Son moteur? C'est son ouverture sur le monde, sa curiosité, son écoute du public : Buffo n'existe que parce que (et lorsque) nous sommes là pour le regarder.

\section{Curiosité, surprise, découverte}

2 «Ah, vous êtes là !» semble nous dire son visage affolé. Puis, la curiosité l'emporte et il vient voir de plus près... Il n'a pas sitôt compris l'utilisation d'un objet, qu'il en aperçoit un autre, inconnu. Il cherche alors à percer son mystère par tous les moyens. Et nous rions : l'utilisation complètement à contre-emploi des objets, mais toujours selon une logique imparable: une trompette c'est une machine à écrire: les pistons sont « touches », le tuyau " rouleau », etc.

Mais Buffo n'est pas un simple d'esprit. Quand il comprend que ses tâtonnements face à ce qui l'entoure nous font rire, il recommence. Mais ça ne marche plus. Ce qui nous amusait c'était sa surprise. Quand il cherche à provoquer volontairement le rire par répétition, on ne rit plus. Et sa déception est à nouveau irrésistible. 


\section{Transparence}

4 Buffo oscille constamment entre sa spontanéité, sa curiosité, son rapport au public. Tous les sentiments qui le traversent, nous émeuvent, et nous amusent. Le clown est « transparent », il nous livre à nu sa tendresse, ses émois, sa perplexité.

5 Il n'y a qu'à voir son empressement à consoler son bébé-violon qui pleure! Et son ravissement devant la famille au complet: papa-contrebasse, maman-violoncelle et bébé-violon. Et pourtant ce dernier était miraculeusement « ressuscité ». Buffo l'avait écrasé par inadvertance, provoquant la stupeur unanime du public. Les spectateurs qui avaient assisté à la conférence, furent peut-être encore plus touchés connaissant l'histoire de ce violon, dénommé : Bob. Bob est un cadeau de la part d'un luthier suisse qui rivalise en qualité avec les stradivarius de Pierre Amoyal!... Et l'attachement d'Howard pour son instrument est visible dans les attentions de Buffo.

\section{Buffo-Howard}

6 Buten-Buffo est musicien, chanteur, ventriloque, danseur... C'est le résultat de longues années de recherche, de travail, et d'essais. C'est aussi des facultés innées : Howard à huit ans amusait déjà les copains ou la famille en faisant le clown, à treize ans, il donnait des leçons de musique, etc.

7 Mais, on ne progresse que par le travail. Et Howard Buten de mépriser les comédiens français (tous ?) qui se reposent sur leurs lauriers une fois sortis du Conservatoire ou de l'Ecole... « Je suis comédien » disent-ils et ça leur suffit.

8 «En Amérique c'est une des rares qualités qu'il prête aux Américains, l'acteur retourne régulièrement à l'école de théâtre, fait des stages « sur le terrain » lorsqu'il prépare un rôle, demande l'avis des collègues sur son propre jeu... Le comédien reste critique envers lui-même, se remet en question et par là même progresse. »

9 C'est ainsi que pas à pas, Buffo est devenu un être vivant.

10 Si Buffo est différent à chaque fois parce que le public change, il est tributaire également de son créateur. Cependant, à aucun moment, on ne voit Buten en scène, uniquement Buffo. Mais un Buffo plus gesticulateur, plus émouvant ou plus distrait.

11 Buten raconte d'une voix calme, posée avec un léger accent américain regardant chacun des auditeurs. Et tout comme on ne retrouve pas Buffo en écoutant Buten, je ne retrouvai pas celui-ci en revoyant celui-là plus tard.

12 Lorsque nous avons revu Howard à la sortie de son spectacle, il signait des autographes. Assis en compagnie de Bob, il répondait aux questions des spectateurs. Il a même promis qu'il passerait voir les étudiants du Théâtre Universitaire s'il se trouvait à nouveau dans la région.

13 Malgré sa notoriété, Howard Buten n'est pas devenu inaccessible pour autant. L'homme nous laissera un souvenir bien aussi marqué que son personnage: l'un par sa discrétion, l'autre par sa tendresse. 
Howard Buten, Buffo
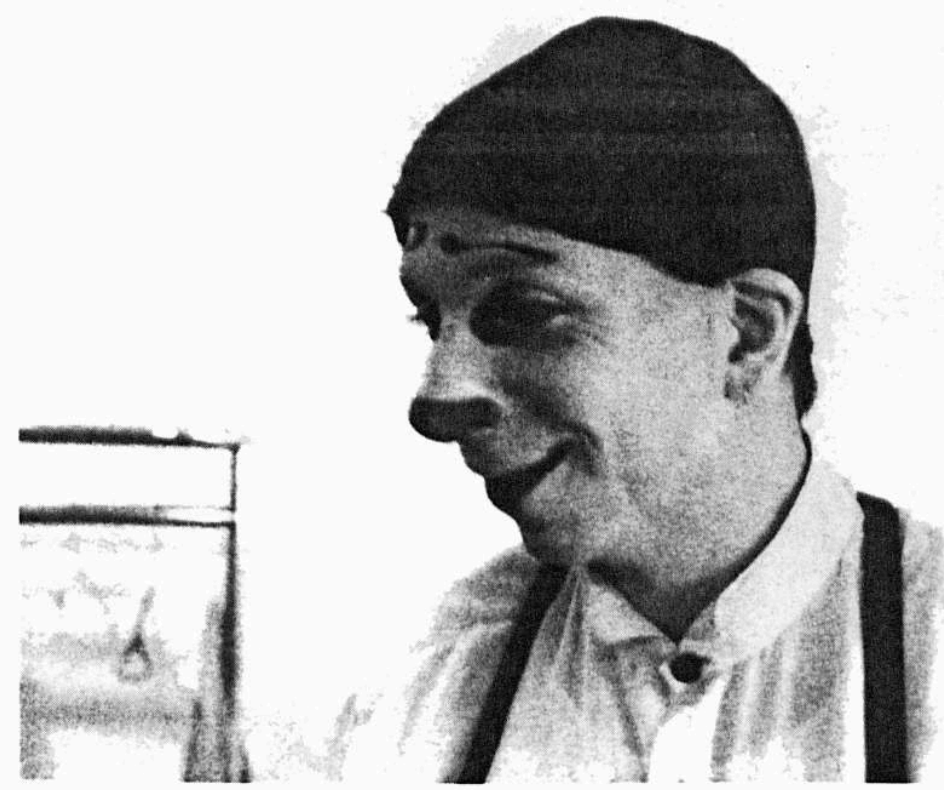

Yves PETIT

\section{NOTES}

1. Publications d'Howard Buten :

- Le coeur sous le rouleau compresseur. Seuil, 1984 (Points virgule 24)

- Histoire de Rofo le clown. Olivier, 1991

- Il faudra bien te couvrir. Seuil, 1989

- Monsieur Butterfly. Seuil, 1989 (Points Virgule 77)

- Quand j'avais cinq ans je m'ai tué. Seuil, 1981 (Points Virgule 3)

\section{AUTEUR}

\section{ANNE-MARIE TOURNIER}

Titulaire d'un D.E.A. de Lettres Classiques, M.A. dans différents lycées, elle anime un club théâtre. 